\title{
New Classification System for Cleft Alveolus: A Computed Tomography-based Appraisal
}

\author{
Philip Mathew ${ }^{1}$, Vivekanand S Kattimani ${ }^{2}$, Rahul VC Tiwari ${ }^{3}$, Mohammad S Iqbal $^{4}$, Aisha Tabassum ${ }^{5}$, Khalid G Syed ${ }^{6}$
}

\begin{abstract}
Aim: The present study proposed a new classification system based on computed tomography (CT) scan appraisal; this enables the surgeon to identify the extent of the defect and helps to execute the proper treatment plan.

Background: Various terminologies and classifications were proposed to understand developmental defects. But none of the existing classifications/nomenclatures used the preoperative radiographic evaluation (i.e., computed tomography scan-CT scan) in the management and prognosis. Various treatments were advocated and practiced successfully for the surgical correction of lip and palate.

Materials and methods: The available CT scans from archives of the Department of Radiology and Oral and Dental Surgery were evaluated (retrospectively) for cleft alveolus and its morphology as per the proposal. The English language literature was searched in the MEDLINE database without date restriction to revise existing literature on numerous classification systems/nomenclatures using MeSH keywords related to cleft lip, palate, alveolus, developmental disturbance, facial clefts, and classification. Existing classification systems were revisited with a note on the drawbacks. After careful examination of morphological patterns of all clefts, the new CT scan-based alveolar cleft classification is proposed depending on the extent of cleft.

Results: The literature revealed a total of twenty-nine classifications of cleft lip and palate starting from the year 1922 to the year 2015 , but none exclusively classified the cleft alveolus based on CT scan observations. The observation of three thousand CT scans showed five types of cleft alveolus, depending on the extent of involvement.

Conclusion: The CT scan-based classification is essential to the surgeon for successful surgical planning of cleft alveolus. The proposed classification is clinically relevant in this digital era for relating surgical outcomes. The three-dimensional viewing of a defect is essential for the surgeon for virtual planning. This paper provides a CT scan-based classification for universal acceptance in this era of digital technology, and CT scan aids in achieving these goals.

Clinical significance: The new proposal is based on preoperative evaluation of cleft using a CT scan. CT scan imaging provides a clear picture of the cleft in three dimensions for the operating surgeon. Advanced technology-enhanced surgical management modalities like CAD/CAM guided templates to support graft for successful management. The classification system will help the medical and surgical fraternity in various aspects. The three-dimensional modeling of defect and printing of a defect model using additive manufacturing technology helps the surgeon for presurgical visualization and virtual planning in a better way. This strategy of defect classification using a CT scan will help obtain better clinical outcomes and patient satisfaction.
\end{abstract}

Keywords: Alveolus, Anomaly, Cleft, Embryology, Nomenclature, Repair.

The Journal of Contemporary Dental Practice (2020): 10.5005/jp-journals-10024-2849

\section{INTRODUCTION}

Various classification systems were proposed from the beginning of the era. ${ }^{1}$ Many surgeons and clinicians came out with different classification systems. Time immemorial, the classification/ nomenclature started with notations so that it can be stored and retrieved digitally. ${ }^{2}$ The wide diversity of cleft lip and palate in terms of clinical presentation makes the universal acceptance of existing classifications difficult, ${ }^{3}$ and specific cleft alveolus classification does not exist.

The cleft alveolus is an entirely separate entity than a cleft of the palate. It should be viewed in the spectrum of cleft lip. ${ }^{4}$ The existing classifications are either combined with lip, palate, or both, because of the nature of cleft development (Table 1). The isolated occurrence of the cleft alveolus is rare, which might be one of the reasons for not having separate classification. The difference of opinion and need for a universally accepted classification made our team think of a computed tomography (CT) scan-based classification system and factors affecting the prognosis before surgical management. The existing literature proposed many treatment modalities, preand postoperative expansion of the maxilla, and schedules for
${ }^{1,3}$ Department of Oral and Maxillofacial Surgery, and Dentistry, Jubilee Mission Medical College Hospital and Research Institute, Thrissur, Kerala, India

${ }^{2}$ Department of Oral and Maxillofacial Surgery, Sibar Institute of Dental Sciences, Guntur, Andhra Pradesh, India

${ }^{4,5}$ Faculty of Applied Medical Sciences, Umm al Qura University, Makkah, Kingdom of Saudi Arabia

${ }^{6}$ Department of Preventive Dental Sciences, College of Dentistry, Prince Sattam Bin Abdul Aziz University, Alkharj, Kingdom of Saudi Arabia

Corresponding Author: Vivekanand S Kattimani, Department of Oral and Maxillofacial Surgery, Sibar Institute of Dental Sciences, Guntur, Andhra Pradesh, India, Phone: +91 9912400988, drvivekanandsk@ gmail.com

How to cite this article: Mathew P, Kattimani VS, Tiwari RVC, et al. New Classification System for Cleft Alveolus: A Computed Tomographybased Appraisal. J Contemp Dent Pract 2020;21(8):942-948.

Source of support: Nil

Conflict of interest: None

() The Author(s). 2020 Open Access This article is distributed under the terms of the Creative Commons Attribution 4.0 International License (https://creativecommons. org/licenses/by-nc/4.0/), which permits unrestricted use, distribution, and non-commercial reproduction in any medium, provided you give appropriate credit to the original author(s) and the source, provide a link to the Creative Commons license, and indicate if changes were made. The Creative Commons Public Domain Dedication waiver (http://creativecommons.org/publicdomain/zero/1.0/) applies to the data made available in this article, unless otherwise stated. 
Table 1: Existing classification chronologically with comments

\begin{tabular}{|c|c|c|c|}
\hline S. no. & Proposed by & Year & Comments \\
\hline 1 & Davis and Ritchie 5 & 1922 & $\begin{array}{l}\text { Based on the alveolus, patients with a unilateral or bilateral cleft of the lip and posterior palate with } \\
\text { intact cleft alveolus fail to fit into a single group. }\end{array}$ \\
\hline 2 & Victor Veau ${ }^{6}$ & 1931 & $\begin{array}{l}\text { Used incisive foramen as an anatomic landmark for the division of types, but overlooked the cleft } \\
\text { patients born with cleft lip, alveolus. }\end{array}$ \\
\hline 3 & Fogh-Andersen ${ }^{7}$ & 1946 & $\begin{array}{l}\text { Based on anatomy and embryology, and the concept of primary and secondary palates involved for } \\
\text { grouping. }\end{array}$ \\
\hline 4 & Kernahan and Stark ${ }^{8}$ & 1958 & Used embryological concepts and primary and secondary palates for description purposes. \\
\hline 5 & Vilar-Sancho ${ }^{9}$ & 1962 & $\begin{array}{l}\text { Used Greek nomenclature for classification and coded congenital cleft lip and cleft palate. It could not } \\
\text { classify many of the cleft subtypes, even though included alveolus as "G" (gnato) with the right, left, } \\
\text { complete, and incomplete. But not adopted worldwide probably because it was in Greek. }\end{array}$ \\
\hline 6 & Harkins et al. ${ }^{10}$ & 1962 & $\begin{array}{l}\text { Based on anatomic segmentation into the pre-palate and the palate with subclasses. The subclasses } \\
\text { used severity, i.e., quantitative measurement of width and extent of cleft as } 1 / 3,2 / 3 \text {, or } 3 / 3 \text {, but no } \\
\text { specific mention of alveolar subclass was made in the classification. }\end{array}$ \\
\hline 7 & Santiago ${ }^{11}$ & 1969 & $\begin{array}{l}\text { Based on digital and alphabetical notification involved all types for the use of machine coding but } \\
\text { not specifically concerning the extent of alveolus as they mentioned either complete or incomplete, } \\
\text { unilateral or bilateral. }\end{array}$ \\
\hline 8 & Dahl $^{12}$ & 1970 & A combination of clefts classification is not possible. \\
\hline 9 & Fogh-Andersen ${ }^{13}$ & 1971 & Modified the original types by adding a new group to feature the median clefts. \\
\hline 10 & Kernahan $^{14}$ & 1971 & $\begin{array}{l}\text { Described using a Y-shaped diagram representing lip, palate, and alveolus. This notification is merely } \\
\text { visual and failed in the application aspect. }\end{array}$ \\
\hline 11 & Elsahy ${ }^{15}$ & 1973 & This is a modified striped $Y$ classification. \\
\hline 12 & Spina $^{16}$ & 1973 & $\begin{array}{l}\text { Described a modification of terminology in international classification by adding Latin term } \\
\text { "foraminal." }\end{array}$ \\
\hline 13 & Balakrishnan ${ }^{17}$ & 1975 & Based on anatomical and embryological representation and was based on Dahl 1970 classification. \\
\hline 14 & Sandham ${ }^{18}$ & 1985 & This is modified from Kernahan and Stark. \\
\hline 15 & Kriens $^{19}$ & 1989 & $\begin{array}{l}\text { Proposed LAHSHAL classification, with acronym lip, alveolus, hard palate, soft palate. The last three } \\
\text { words will be for the left side, and the first three words will be for the right side. Because of its verbal } \\
\text { communication in different languages its use is limited. }\end{array}$ \\
\hline 16 & Silva Filho et al. ${ }^{20}$ & 1992 & $\begin{array}{l}\text { Modified Spina classification with the inclusion of group } \mathrm{I} / \mathrm{III} \text { for stratification, but it did not assess cleft } \\
\text { severity (cleft size) and the capacity for prognosis estimation. }\end{array}$ \\
\hline 17 & Schwartz et al. ${ }^{21}$ & 1993 & Proposed an RPL system with numerical coding for easy presentation. \\
\hline 18 & Koch et al. ${ }^{22}$ & 1995 & $\begin{array}{l}\text { Proposed LAHSN (lip, alveolus, hard and soft palates, and nose) based on the extent in all three } \\
\text { directions. }\end{array}$ \\
\hline 19 & Smith et al. ${ }^{23}$ & 1998 & $\begin{array}{l}\text { Modified classification of Kernahan striped to compensate for the shortcomings and added additional } \\
\text { types. But it did not describe the submucous cleft palate levels nor the alveolus. }\end{array}$ \\
\hline 20 & Ortiz-Posadas et al. ${ }^{24}$ & 2001 & Developed mathematical expression for characterization to reflect overall complexity. \\
\hline 21 & Castilla and Orioli ${ }^{25}$ & 2004 & $\begin{array}{l}\text { Presented ECLAMC numerical coding system. This classification presented numerical code for } \\
\text { all possible varieties and extent, but did not mention the prognostic factors. It is similar to our } \\
\text { presentation, but little variation exists in the use of terminology. }\end{array}$ \\
\hline 22 & Liu et al. ${ }^{26}$ & 2007 & $\begin{array}{l}\text { Developed (LAPAL system) a five-digit numerical recording system based on Kernahan "Y" } \\
\text { classification, Smith-modified Kernahan "Y" classification, and the RPL system. The extent of defects } \\
\text { was represented by Arabic numerals ( } 0-4) \text {. }\end{array}$ \\
\hline 23 & Koul $^{3}$ & 2007 & $\begin{array}{l}\text { Used anatomical nomenclature (text) and symbols for proposal. It looks complicated because of the } \\
\text { symbols involved in the presentation. }\end{array}$ \\
\hline 24 & $\begin{array}{l}\text { Yuzuriha and Mul- } \\
\text { liken }{ }^{27}\end{array}$ & 2008 & $\begin{array}{l}\text { Described less form labial clefts with measurements of } 3 \mathrm{~mm} \text { more or less as micro, mini-micro. This } \\
\text { presentation includes the operative guide for optimal operative technique depending on the severity } \\
\text { of the cleft. }\end{array}$ \\
\hline \multirow[t]{2}{*}{25} & Rossell-Perry ${ }^{28}$ & 2009 & $\begin{array}{l}\text { Proposed classification of severity and diagram for cleft description. Also discussed the selection of } \\
\text { proper technique depending on the class of cleft. }\end{array}$ \\
\hline & & & $\begin{array}{l}\text { The severity of the cleft was assessed by the width of cleft and sum of width of the two palatal } \\
\text { segments at the junction of soft and hard palates to indicate the tissue deficiency. Based on } \\
\text { measurements, the index classifies three degrees of severity for the cleft palate but does not consider } \\
\text { alveolus for the same. }\end{array}$ \\
\hline 26 & Khan et al. ${ }^{29}$ & 2013 & $\begin{array}{l}\text { Revised Smith-modified Kernahan "Y" classification with submucous cleft varieties, but these } \\
\text { subclassifications did not consider alveolus. }\end{array}$ \\
\hline
\end{tabular}

Contd... 
Contd...

\begin{tabular}{|c|c|c|c|}
\hline S. no & Proposed by & Year & Comments \\
\hline 27 & Agarwal $^{30}$ & 2014 & $\begin{array}{l}\text { Modified Indian classification described by Balakrishnan into groups with a notation of ' }+ \text { ' for unilat- } \\
\text { eral and bilateral combinations and abbreviations of the involved part. }\end{array}$ \\
\hline 28 & Luijsterburg et al. ${ }^{31}$ & 2014 & $\begin{array}{l}\text { Based on patho-embryological events like fusion, differentiation, and fusion and differentiation } \\
\text { defects of the primary and secondary palates. }\end{array}$ \\
\hline 29 & Allori et al. ${ }^{1}$ & 2015 & Proposed a universal structured form in the form of CLAP notation. \\
\hline
\end{tabular}

Table 2: Proposed classification for alveolar cleft based on preoperative 3D computed tomography

\begin{tabular}{|c|c|c|c|c|}
\hline Class & Description & Nature & Comments & Prognosis \\
\hline I & $\begin{array}{l}\text { One-third alveolus } \\
\text { involvement }\end{array}$ & $\begin{array}{l}\text { Submucosal, isolated, } \\
\text { unilateral, or bilateral }\end{array}$ & $\begin{array}{l}\text { Tooth involved may be erupted/ } \\
\text { partially erupted/impacted }\end{array}$ & Good \\
\hline II & $\begin{array}{l}\text { Two-thirds alveolus } \\
\text { involvement }\end{array}$ & $\begin{array}{l}\text { Submucosal, isolated, } \\
\text { unilateral, or bilateral }\end{array}$ & $\begin{array}{l}\text { Tooth involved may be erupted/ } \\
\text { partially erupted/impacted }\end{array}$ & $\begin{array}{l}\text { Good, requires prosthetic or } \\
\text { orthodontic treatment }\end{array}$ \\
\hline III & $\begin{array}{l}\text { Complete alveolus } \\
\text { involvement }\end{array}$ & $\begin{array}{l}\text { Isolated, unilateral, or } \\
\text { bilateral }\end{array}$ & $\begin{array}{l}\text { Tooth involved may be erupted/ } \\
\text { partially erupted/impacted }\end{array}$ & $\begin{array}{l}\text { Good, requires prosthetic or } \\
\text { orthodontic treatment }\end{array}$ \\
\hline IV & $\begin{array}{l}\text { Communication with } \\
\text { nasal floor }\end{array}$ & $\begin{array}{l}\text { unilateral, or bilateral } \\
\text { complete }\end{array}$ & $\begin{array}{l}\text { Tooth involved may be partially } \\
\text { erupted/impacted }\end{array}$ & $\begin{array}{l}\text { Depends on the width of cleft and } \\
\text { requires prosthetic or orthodontic } \\
\text { treatment }\end{array}$ \\
\hline V-A & $\begin{array}{l}\text { Concomitant with lip } \\
\text { and palate }\end{array}$ & Associated with Class I & $\begin{array}{l}\text { Any lip or palate cleft as described } \\
\text { previously, might be associated with } \\
\text { Class I alveolar cleft }\end{array}$ & $\begin{array}{l}\text { Good with alveolus, but the overall } \\
\text { result depends on the associated } \\
\text { nature of clefts }\end{array}$ \\
\hline V-B & $\begin{array}{l}\text { Concomitant with lip } \\
\text { and palate }\end{array}$ & Associated with Class II & $\begin{array}{l}\text { Any lip or palate cleft as described } \\
\text { previously, might be associated with } \\
\text { Class II alveolar cleft }\end{array}$ & $\begin{array}{l}\text { Good with alveolus, but the overall } \\
\text { result depends on the associated } \\
\text { nature of clefts }\end{array}$ \\
\hline $\mathrm{V}-\mathrm{C}$ & $\begin{array}{l}\text { Concomitant with lip } \\
\text { and palate }\end{array}$ & Associated with Class III & $\begin{array}{l}\text { Any lip or palate cleft as described } \\
\text { previously, might be associated with } \\
\text { Class III alveolar cleft }\end{array}$ & $\begin{array}{l}\text { Depends on the width of cleft and the } \\
\text { associated nature of clefts and may } \\
\text { require a second surgery }\end{array}$ \\
\hline
\end{tabular}

alveolar cleft grafting. Grafting of cleft alveolus uses autologous and synthetic bone substitute materials. With our knowledge, none of the published studies have given specific graft material nor advised a standard surgical technique in a particular defect class.

This study proposed a CT scan-based new classification appraisal for cleft alveolus exclusively, after morphological examination of cleft patterns using CT scans (archives of more than 3000 alveolar clefts-both unilateral and bilateral cases) in our center. This study delineates our center management strategy to understand the prognostic factors depending on the new CT-based cleft classification.

\section{Materials and Methods}

The CT scans of the cleft patients with an age range of 9-20 years from the archives of the Department of Radiology and Oral and Dental Surgery were included for evaluation. The data were evaluated for cleft morphology, and other factors were noted retrospectively to understand the outcomes of surgery. Various cleft defects were appraised and noted as per the new classification. The grafting, defect correction, and its outcomes were noted for surgical emphasis as per our center's protocol based on CT scan.

The English language literature was searched in the MEDLINE database without date restriction to revise existing literature on numerous classification systems using MeSH keywords related to cleft lip, palate, alveolus, developmental disturbance, facial clefts, classification, and nomenclature. Cross-reference search was performed in various plastic and reconstructive journals, head, and neck, oral and maxillofacial journals for comprehensiveness.

\section{Results}

The CT scan examination revealed five types of defects. These defects were grouped into five classes, annexed with subclasses (Table 2). The literature revealed a total of twenty-nine classifications/nomenclature of cleft lip and palate since the year 1922 till 2015 (Table 1). Still, none exclusively described cleft alveolus based on CT scan observations.

\section{Discussion}

Historically, cleft classification or nomenclature descriptions were given by Davis and Ritchie ${ }^{5}$ way back in the year 1922, followed by many other studies ${ }^{1,3,6-31}$, as noted in Table 1 with comments. But none of these existing classifications/nomenclatures mentioned cleft alveolus appraisal based on preoperative CT scan examination. The recent explanation of cleft alveolus has noted the historical discrimination of distinguishing it from the palate has not been made clear, which needs to be corrected for proper attention and treatment. ${ }^{4}$ The inadequacies of each classification are mentioned in Table 1 with comments. The advances in radiographic investigations from plain to three-dimensional imaging made the preoperative evaluation and virtual planning more easy and accurate. In the absence of a patient, the surgeon will be able to plan it accurately and discuss with peers before surgery for successful execution as planned using a CT scan.

\section{Proposed Cleft Alveolus Classification}

The new classification proposal is based on the preoperative CT scan views of defect patterns and morphology. In the proposed classification, cleft alveolus is divided into five major classes as Class I 
to Class V with three subclasses in Class V (Table 2), either unilateral/ bilateral depending on the extent of alveolar cleft measuring from the crestal bone of adjacent teeth. The schematic diagram and corresponding representational CT scan images delineate the proposed system of classification for better understanding (Figs $1 \mathrm{~A}$ to $4 \mathrm{~A}$ and Figs $1 \mathrm{~B}$ to $4 \mathrm{~B}$ ). This system considers the depth and width of cleft and thereby helps the operating surgeon for proper planning of the treatment. In concomitant clefts of lip and palate (proposed Class $V$ and its three subdivisions), the surgeon or clinician can adopt any one of the classifications depending on their geography and school of thought for the treatment. Many of our clefts fall in Class $V$ with subclasses; this might require a second surgery for an esthetic correction after the growth of the patient ceases.

The timing for repair of cleft lip and palate were wellestablished facts in the published literature. ${ }^{32-35}$ The grafting for alveolus was also proposed and practiced widely. ${ }^{36-39}$ But none of the published literature classified cleft alveolus based on preoperative CT scan findings in three dimensions. The advances in diagnostic technology, both prenatal and postnatal, to assess developmental and growth disturbances for predicting anomalies are much better than earlier. Anomaly scanning of parents has reduced the newer incidence of clefts reasonably. These reducing trends in the defects might be one of the reasons for not having enough number of cases to standardize the existing classification or providing a newer appraisal. ${ }^{40}$ The historical presentations were based on clinical and intraoperative findings. Liu et al., ${ }^{26}$ Yuzuriha and Mulliken, ${ }^{27}$ Rossell-Perry, ${ }^{28}$ Khan et al., ${ }^{29}$ and Agarwal ${ }^{30}$ classifications have similarities with the proposed classification, but none have a specific description of cleft alveolus using CT appraisal. The present appraisal is distinct and provides better prognostic features. The advances in technology help to create a virtual model for the reconstruction of these defects using CAD/CAM.

\section{Our Center's Protocol for the Management}

Description of treatment options as per CT-based classification is as follows:

Classes I and II- use of cancellous alveolar bone grafting, platelet rich fibrin (PRF) membrane placed along the oral surface of the graft. Class III- use of corticocancellous alveolar bone grafting to provide mechanical strength to the graft. PRF membrane was placed along the oral surface of the graft. According to the subdivisions of the proposed classes, the involvement of the nasal floor and depression of the alar base on the affected side(s) should be considered. If the

\section{A}
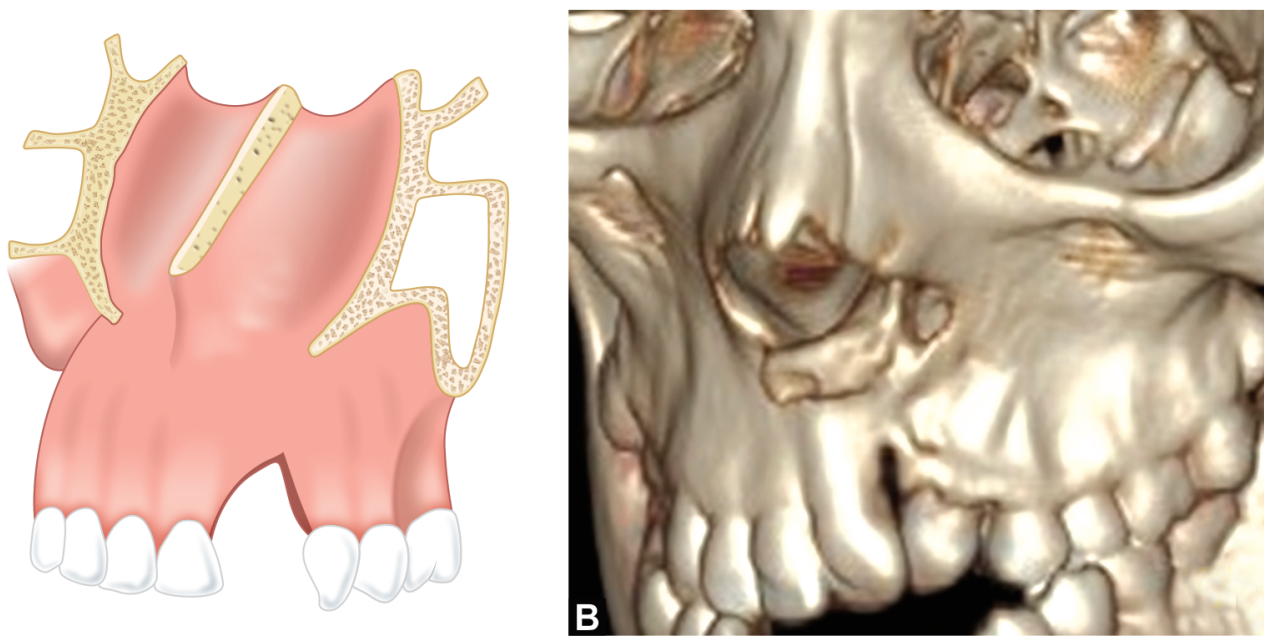

Figs 1 A and B: (A) Schematic diagram and (B) representative 3D CT scan image showing Class I alveolar defect

A
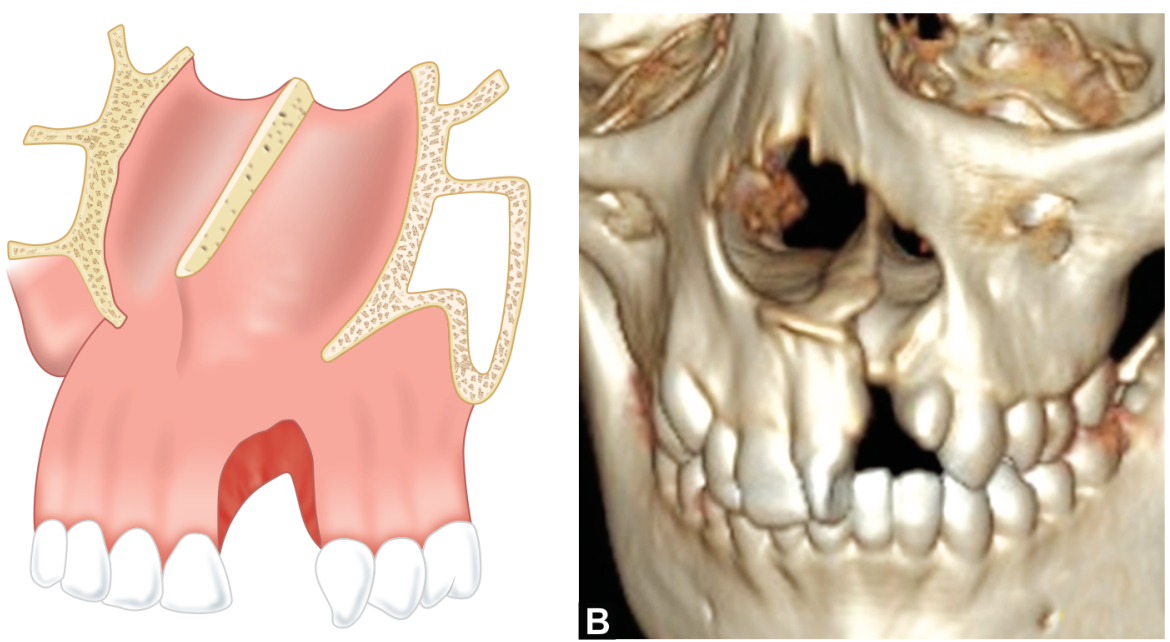

Figs 2A and B: (A): Schematic diagram and (B) representative 3D CT scan image showing Class II alveolar defect 

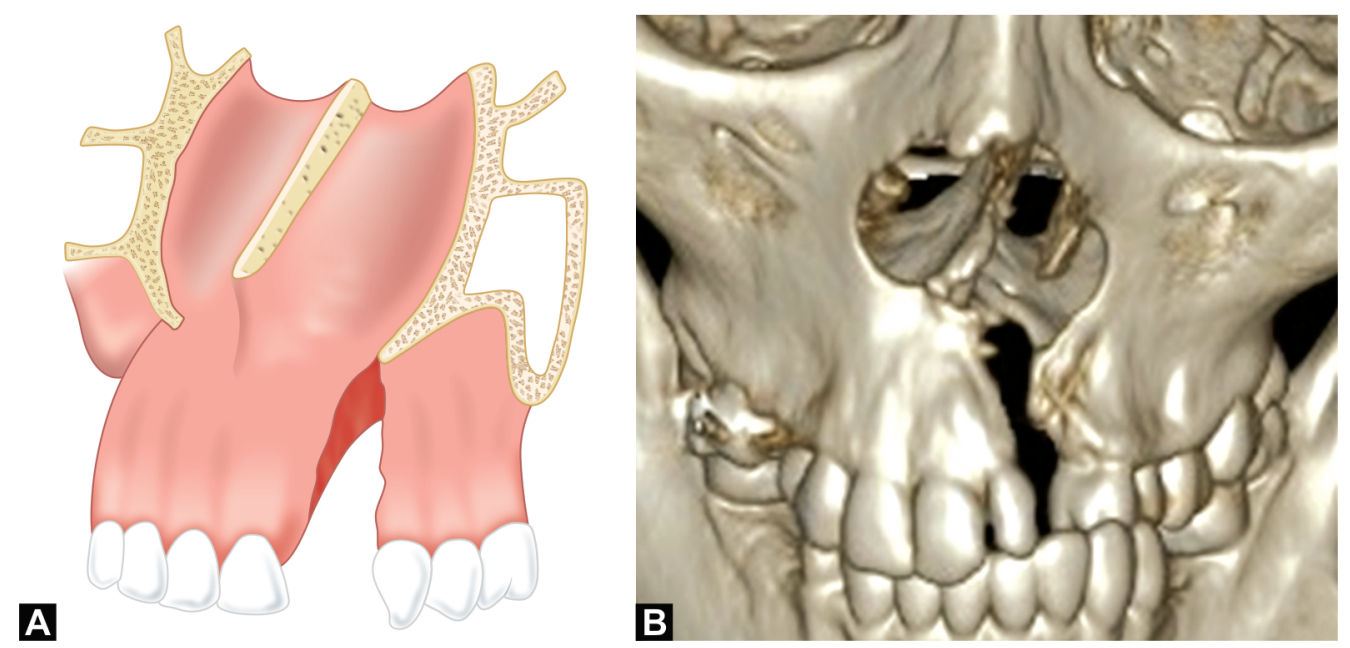

Figs 3A and B: (A) Schematic diagram and (B) representative 3D CT scan image showing Class III alveolar defect
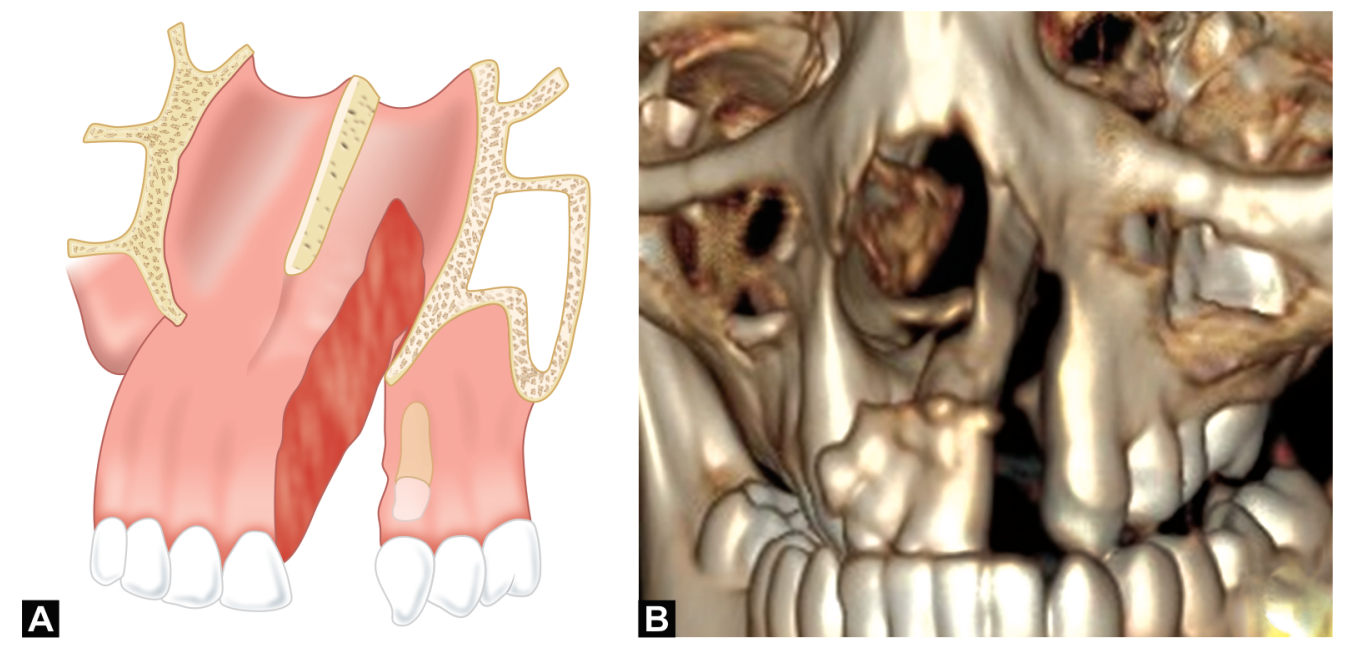

Figs 4A and B (: A) Schematic diagram and (B) representative 3D CT scan image showing Class IV alveolar defect

nasal floor is involved, an additional PRF membrane has to be placed along the nasal floor mucosa and a thin piece of cortical bone is used to separate the nasal mucosa up to the level of nasal floor, for example, to the same height of the opposite unaffected side in the unilateral cleft. This cortical bone piece acts as resistance while packing the defective area with cancellous bone. The pyriform rim on the affected side[s] in the region of the depressed alar base also needs to be grafted with corticocancellous bone.

\section{Factors Affecting the Prognosis of Cleft Alveolus}

The prognosis of cleft alveolus surgery is multifactorial. It can be broadly divided into operator and patient factors. Patient factors include nature and type of cleft. The width of the cleft is considered as one of the critical factors for the success of the graft. Various surgical grafting techniques and adjunct presurgical treatment modalities like naso-alveolar molding for aligning the cleft segments are practiced by clinicians. ${ }^{12}$ Grafting strategies of the cleft are well published in the literature. ${ }^{40}$

\section{Limitations of the Study}

The study data were collected retrospectively, so the correlations of various factors for the outcome analysis were not considered.
The study also not considered scans of older age-group patients (above 20 years). The surgical modalities are not compared for the esthetic outcome, nor the data available were considered in the surgical and follow-up notes. The prospective study is ongoing to delineate the various factors affecting the prognosis of cleft grafting, taking into consideration new CT scan-based classification. The photographic outcome and patient satisfaction index studies are also ongoing in our center. This is preliminary work on the archival data of CT scan-based morphological examination of the cleft alveolus.

\section{Conclusion}

The proposed classification is useful for research and clinical purposes. Meticulous planning is required for the successful execution of surgery. By knowing the posterior extent of the cleft in the hard palate using a CT scan, one should be cautious to avoid overpacking of the defect. The new proposal is unique and provides insights into cleft alveolus may be isolated or concomitant. The prognosis of surgery invariably depends on the nature of clefts. It can be used for future reference in systematic reviews. The standardization of defects will provide proper evidence for treatment modalities in this evidence-based digital era. 


\section{Author Contributions}

Philip Mathew and Vivekanand S Kattimani drafted the protocol and developed a search strategy; Team 1, Philip Mathew, Vivekanand S Kattimani, Rahul Vinay Chandra Tiwari, and Team 2, Mohammad Shahid Iqbal, Aisha Tabassum, Khalid Gufran Syed, searched for literature. Vivekanand S Kattimani and Philip Mathew selected articles to include in this analysis. Philip Mathew and Rahul Vinay Chandra Tiwari performed archival data extraction for analysis. Mohammad Shahid Iqbal, Aisha Tabassum, and Khalid Gufran Syed obtained copies of publications of all included studies. Vivekanand S Kattimani and Rahul Vinay Chandra Tiwari extracted data from publications. Mohammad Shahid Iqbal and Aisha Tabassum verified the data entered for review. Vivekanand S Kattimani, Rahul Vinay Chandra Tiwari, and Philip Mathew interpreted the CT scan data; Philip Mathew and Vivekanand S Kattimani drafted the final evaluation and interpretations. All the authors read and approved the final version of the manuscript.

\section{Acknowledgments}

The authors thank the colleagues of the Radiology Department for their help in retrieving the CT scans for assessment and for extending support to provide the needed CT scan sections for appraisal. The authors also thank colleagues Dr Lakshmi Manas and Dr Anita for their inputs during manuscript revision and Ms. Nandini for helping with diagrammatic presentation.

\section{References}

1. Allori AC, Mulliken JB, Meara JG, et al. Classification of cleft lip/palate: then and now. Cleft Palate Craniofac J 2017;54(2):175-188. DOI: 10.1597/14-080.

2. Allori AC. Striped-Y redux: redesigning pictographic notational systems for the digital age. Dent Oral Craniofac Res 2017;3(5). DOI: 10.15761/DOCR.1000218.

3. Koul R. Describing cleft lip and palate using a new expression system. Cleft Palate Craniofac J 2007;44(6):585-589. DOI: 10.1597/06-111.1.

4. Wirtz N, Sidman J, Block W. Clefting of the alveolus: emphasizing the distinction from cleft palate. Am J Perinatol 2016;33(6):531-534. DOI: 10.1055/s-0036-1572537.

5. Davis JS, Ritchie HP. Classification of congenital clefts of the lip and palate: with a suggestion for recording these cases. JAMA 1922;79(16):1323-1327. DOI: 10.1001/jama.1922.02640160043014.

6. Division palatine: Anatomie-chirurgie phonétique. By Victor Veau, Chirurgien de l'Hǒpital des Enfants assistés, with the collaboration of Mme. S. Borel. Large 8vo. Pp. 568 + viii, with 786 illustrations. 1931. Paris: Masson et Cie. Fr. 140 - 1932 - BJS - Wiley Online Library. Available at https://onlinelibrary.wiley.com/doi/abs/10.1002/bjs.1800207829. Accessed September 18, 2019.

7. Fogh-Andersen P. Harelip and cleft palate; 1,000 patients submitted to operation. Acta Chir Scand 1946;94(3/4):213-242.

8. Kernahan DA, Stark RB. A new classification for cleft lip and cleft palate. Plast Reconstr Surg Transplant Bull 1958;22(5):435-441. DOI: 10.1097/00006534-195811000-00001.

9. Vilar-Sancho B. A proposed new international classification of congenital cleft lip and cleft palate. Plast Reconstr Surg Transplant Bull 1962;30(2):263-266. DOI: 10.1097/00006534-196208000-00005.

10. Harkins CS, Berlin A, Harding RL, et al. A classification of cleft lip and cleft palate. Plast Reconstr Surg Transplant Bull 1962;29(1):31-39. DOI: 10.1097/00006534-196201000-00005.

11. Santiago A. Classification of cleft lip and palate for machine record coding. Cleft Palate J 1969;6:434-439.

12. Dahl E. Craniofacial morphology in congenital clefts of the lip and palate. an x-ray cephalometric study of young adult males. Acta Odontol Scand 1970;28(Suppl 57):11+.
13. Fogh-Andersen P. Epidemiology and etiology of clefts. Birth Defects Orig Artic Ser 1971;7(7):50-53.

14. Kernahan DA. The striped Y-a symbolic classification for cleft lip and palate. Plast Reconstr Surg 1971;47(5):469-470. DOI: 10.1097/00006534-197105000-00010.

15. Elsahy NI. The modified striped $\mathrm{Y}$-a systematic classification for cleft lip and palate. Cleft Palate J 1973;10:247-250.

16. Spina V. A proposed modification for the classification of cleft lip and cleft palate. Cleft Palate J 1973;10:251-252.

17. Pandya NJ, Balakrishnan C. Indian classification of cleft lip and palate. Plast Reconstr Surg 1977;59(3):458-459. DOI: 10.1097/00006534197703000-00077.

18. Sandham A. Classification of clefting deformity. Early Hum Dev 1985;12(1):81-85. DOI: 10.1016/0378-3782(85)90140-9.

19. Kriens O. LAHSHAL: a concise documentation system for cleft lip, alvolus and palate diagnoses. What is cleft lip and palate? A multidisciplinary update. Stuttgart: Thieme; 1989.

20. Silva Filho OG, da., Ferrari Júnior FM, Rocha DL, et al. Classificaçäo das fissuras lábio-palatais: breve histórico, consideraçöes clínicas e sugestäo de modificaçäo. Rev Bras Cir 1992;82(2):59-65.

21. Schwartz S, Kapala JT, Rajchgot H, et al. Accurate and systematic numerical recording system for the identification of various types of lip and maxillary clefts (RPL system). Cleft Palate Craniofac J 1993;30(3):330-332. DOI: 10.1597/1545-1569_1993_030_0330_ aasnrs_2.3.co_2.

22. Koch H, Grzonka M, Koch J. Cleft malformation of lip, alveolus, hard and soft palate, and nose (LAHSN)-a critical view of the terminology, the diagnosis and gradation as a basis for documentation and therapy. Br J Oral Maxillofac Surg 1995;33(1):51-58. DOI: 10.1016/02664356(95)90088-8.

23. Smith AW, Khoo AK, Jackson IT. A modification of the Kernahan "Y" classification in cleft lip and palate deformities. Plast Reconstr Surg 1998;102(6):1842-1847. DOI: 10.1097/00006534-199811000-00005.

24. Ortiz-Posadas MR, Vega-Alvarado L, Maya-Behar J. A new approach to classify cleft lip and palate. Cleft Palate Craniofac J 2001;38(6): 545-550. DOI: 10.1597/1545-1569_2001_038_0545_anatcc_2.0. Co_2.

25. Castilla EE, Orioli IM. ECLAMC: the latin-american collaborative study of congenital malformations. Community Genet 2004;7(2-3):76-94. DOI: 10.1159/000080776.

26. Liu Q, Yang M-L, Li Z-J, et al. A simple and precise classification for cleft lip and palate: a five-digit numerical recording system. Cleft Palate Craniofac J 2007;44(5):465-468. DOI: 10.1597/06-140.1.

27. Yuzuriha S, Mulliken JBMinor-form. Microform, and minimicroform cleft lip: anatomical features, operative techniques, and revisions. Plast Reconstr Surg 2008;122(5):1485-1493. DOI: 10.1097/ PRS.0b013e31818820bc.

28. Rossell-Perry P. New diagram for cleft lip and palate description: the clock diagram. Cleft Palate Craniofac J 2009;46(3):305-313. DOI: 10.1597/08-070.1.

29. Khan $\mathrm{M}$, Ullah $\mathrm{H}, \mathrm{Naz} \mathrm{S}$, et al. A revised classification of the cleft lip and palate. Can J Plast Surg 2013;21(1):48-50. DOI: 10.1177/229255031302100102.

30. Agarwal S, Yadav S, Shah NV, et al. Correction of bilateral impacted mandibular canines with a lip bumper for anchorage reinforcement. Am J Orthod Dentofacial Orthop 2013;143(3):393-403. DOI: http:// dx.doi.org/10.1016/j.ajodo.2011.12.030.

31. Luijsterburg AJM, Rozendaal AM, Vermeij-Keers C. Classifying common oral clefts: a new approach after descriptive registration. Cleft Palate Craniofac J 2014;51(4):381-391. DOI: 10.1597/156951.4.493.

32. Bill J, Proff $P$, Bayerlein $T$, et al. Treatment of patients with cleft lip, alveolus and palate-a short outline of history and current interdisciplinary treatment approaches. J Craniomaxillofac Surg 2006;34(Suppl 2):17-21. DOI: 10.1016/S1010-5182(06) 60005-X.

33. Farronato G, Kairyte L, Giannini L, et al. How various surgical protocols of the unilateral cleft lip and palate influence the facial growth and 
possible orthodontic problems? which is the best timing of lip, palate and alveolus repair? literature review. Stomatologija 2014;16(2): 53-60.

34. Marcus JR, Allori AC, Santiago PE. Principles of cleft lip repair: conventions, commonalities, and controversies. Plast Reconstr Surg 2017;139(3):764e-780ee. DOI: 10.1097/PRS.0000000 000003148.

35. Bhattacharya S, Khanna V, Kohli R. Cleft lip: the historical perspective. Indian J Plast Surg 2009;42(Suppl):S4-S8. DOI: 10.4103/09700358.57180.

36. Kyung H, Kang N. Management of alveolar cleft. Arch Craniofac Surg 2015;16(2):49-52. DOI: 10.7181/acfs.2015.16.2.49.
37. Coots BK. Alveolar bone grafting: past, present, and new horizons. Semin Plast Surg 2012;26(4):178-183. DOI: 10.1055/s-0033-1333887.

38. Santiago PE, Schuster LA, Levy-Bercowski D. Management of the alveolar cleft. Clin Plast Surg 2014;41(2):219-232. DOI: 10.1016/ j.cps.2014.01.001.

39. Eppley BL, Sadove AM. Management of alveolar cleft bone grafting-state of the art. Cleft Palate Craniofac J 2000;37(3):229-233. DOI: 10.1597/1545-1569_2000_037_0229_moacbg_2.3.co_2.

40. Stasiak M, Wojtaszek-Słomińska A, Racka-Pilszak B. Current methods for secondary alveolar bone grafting assessment in cleft lip and palate patients - A systematic review. Journal of Cranio-Maxillofacial Surgery 2019;47(4):578-585. DOI: 10.1016/j.jcms.2019.01.013. 